\title{
Clinical profile of patients with anemia
}

\author{
K. S. Lamsal \\ Department of Internal Medicine, Tribhuvan University Teaching Hospital, Kathmandu, Nepal. \\ Correspondence to: K. S. Lamsal, Department of Internal Medicine, Tribhuvan University Teaching Hospital, Kathmandu, \\ Nepal. (Phone)-00977-01-4810412, (Mobile)-00977-9851090676 \\ Email: lamsalkamal@hotmail.com
}

\begin{abstract}
Introduction: Anemia itself is not a disease but a clinical feature of some other underlying problems and leads to hypoxia and a wide range of clinical consequences. In a tertiary center like Tribhuvan University Teaching Hospital (TUTH), many patients admitted in medical wards have low hemoglobin. The objective of this study is to determine the etiology and evaluate the different components of clinical profile of the patients having anemia in medical wards of TUTH.

Methods: Patients having hemoglobin less than 10 in the medical wards of TUTH were enrolled in the study. Estimation of hemoglobin and other investigations were done in hematology lab of TUTH. Data were obtained by history taking, examination findings and investigation reports and analysis was done by statistical software SPSS $11.5 \mathrm{v}$.

Results: Among the 237 patients, 138 were male and 99 were female. The commonest age group was $40-49$ years. The average hemoglobin was $7.8 \mathrm{gm} \%$, the lowest being $2.8 \mathrm{gm} \%$. Peripheral blood smear showed hypochromic picture in 140, macrocytic picture in 26 and the morphology was normocytic normochromic in 71 cases. Variceal bleeding leading to anemia was seen in 52, NSAID induced GI bleeding in 22 , peptic ulcer in 18 , hookworm infestation in 6 , nutritional iron deficiency and anemia of chronic diseases in remaining cases. Among the 26 cases having macrocytic anemia, 11 had megaloblastic changes in bone marrow examination and 6 had vitamin $B_{12}$ deficiency and 5 had folate deficiency. Among the 71 patients having normocytic normochromic blood picture, 8 had hemolytic anemia, 11 had aplastic anemia and remaining were having anemia of chronic disease mainly chronic kidney disease. Regarding treatment, 84 patients were transfused blood. Out of total 237 patients included in the study, in-hospital mortality was 28 .

Conclusions: Anemia is associated with a variety of diseases. As chronic blood loss and iron deficiency are among the leading causes of anemia, hypochromic and microcytic picture was the predominant picture in peripheral blood smear. Among the patients having normocytic normochromic blood picture, majority were having chronic kidney disease which may be due to the fact that TUTH is a tertiary referral centre for chronic renal failure. In-hospital mortality due to anemia alone is lower in tertiary care centers, but the mortality in our study is due to associated co-morbid conditions like chronic renal failure and variceal upper GI bleeding.
\end{abstract}

Keywords: Anemia, hemoglobin, iron deficiency.

\section{Introduction}

Hematology is simply a branch of medicine related to different categories of physiological, pathological and clinical conditions and diseases related to components of blood- red blood cells, white blood cells and platelets. Anemia is the most commonly found condition in hematology and is defined as a decrease in red blood cell mass (RBC) or hemoglobin due to variable causes. ${ }^{1}$ Varying degrees of anemia can have a wide range of clinical consequences.

The two major approaches of classifying anemia include the "kinetic" approach which involves evaluating production and destruction of red blood cells using 
reticulocytes as an important parameter and the "morphologic" approach which groups anemia by red blood cell size into microcytic if the cells are smaller than normal (under $80 \mathrm{fl}$ ), normocytic if they are of normal size (80-100 fl) and macrocytic if they are larger than normal (over $100 \mathrm{fl}$ ). ${ }^{2,4}$

Iron deficiency anemia is the most common type of anemia overall and it has many causes. It is caused by insufficient dietary intake, especially in children and women in the developing countries or poor absorption of iron to replace losses from menstruation or losses due to diseases. ${ }^{3,5}$ Worldwide, the most common cause of iron deficiency anemia is parasitic infestation usually hookworm. ${ }^{2}$ Normocytic anaemia occurs when the hemoglobin level is decreased, but the red blood cell size remains normal as in acute blood loss, anemia of chronic disease, aplastic anemia and hemolytic anemia. Megaloblastic anemia is due to a deficiency of either vitamin $B_{12}$ or folic acid (or both). Mild to moderate form of deficiency anemia is treated by supplementation with specific nutrients like ferrous sulfate, folic acid or vitamin $\mathrm{B}_{12}$; whereas anemia associated with chemotherapy or renal and other chronic diseases can be treated by recombinant erythropoietin to stimulate red cell production. In severe cases of anemia, or with ongoing blood loss, a blood transfusion is necessary. ${ }^{1,2,4}$

Four randomized controlled clinical trials have been conducted to evaluate aggressive versus conservative transfusion strategies in critically ill patients. All of them failed to find a benefit with more aggressive transfusion strategies. ${ }^{6-9}$ In addition, at least two retrospective studies have shown increases in adverse clinical outcomes with more aggressive transfusion strategies. ${ }^{10,11}$

The use of HBO is indicated when oxygen delivery to tissue is not sufficient in patients who cannot be transfused for medical or religious reasons. In 2002, Van Meter reviewed the publications surrounding the use of HBO in severe anemia and found that all publications report a positive result. $^{12}$

\section{Methods}

The study was carried out in the medical wards of TUTH. Total patients included in the study numbered 237. Patients having hemoglobin less than 10 were enrolled in the study from $1^{\text {st }}$ January to $30^{\text {th }}$ December 2008 . Further information was obtained from detailed history taking and thorough physical examination. Estimation of hemoglobin and other investigations were done in hematology lab of TUTH. The important investigations included complete blood count including estimation of reticulocyte count and peripheral blood smear. Other investigations done in selected cases were osmotic fragility test, $\mathrm{Hb}$ electrophoresis, Coomb's test, Vitamin $\mathrm{B}_{12}$ and folate assays, iron profile, flow cytometry, stool examination, upper GI endoscopy, colonoscopy, bone marrow examination, ultrasound of abdomen and pelvis, chest $\mathrm{x}$-ray, liver function tests, renal function tests, etc (Table 1). Data obtained by history taking, examination findings and investigation reports were entered into computer and analysis was done by statistical software SPSS $11.5 \mathrm{v}$.

Table 1: Total investigations sent during the study

$\begin{array}{lll}\text { S. No. } & \text { Investigations done } & \text { Applied to } \\ \text { 1. } & \text { Complete blood count } & \text { All patients } \\ \text { 2. } & \text { Reticulocyte count } & \text { All patients } \\ \text { 3. } & \text { Peripheral blood smear } & \text { All patients } \\ \text { 4. } & \text { Osmotic fragility test } & \text { Selected patients } \\ \text { 5. } & \text { Hb electrophoresis } & \text { Selected patients } \\ \text { 6. } & \text { Coomb 's test } & \text { Selected patients } \\ \text { 7. } & \text { Vitamin B } \text { assay }_{\text {12 }} & \text { Selected patients } \\ \text { 8. } & \text { Folate assay } & \text { Selected patients } \\ \text { 9. } & \text { Iron profile } & \text { Selected patients } \\ \text { 10. } & \text { Flow cytometry } & \text { Selected patients } \\ \text { 11. } & \text { Stool examination } & \text { Selected patients } \\ \text { 12. } & \text { Upper GI endoscopy } & \text { Selected patients } \\ \text { 13. } & \text { Colonoscopy } & \text { Selected patients } \\ \text { 14. } & \text { Bone marrow exam } & \text { Selected patients } \\ \text { 15. } & \text { USG abdomen/pelvis } & \text { Selected patients } \\ \text { 16. } & \text { Chest X-ray } & \text { Selected patients } \\ \text { 17. } & \text { Liver function tests } & \text { Selected patients } \\ \text { 18. } & \text { Renal function tests } & \text { Selected patients } \\ \text { 19. } & \text { Urine routine } & \text { Selected patients }\end{array}$

\section{Results}

Altogether 237 patients were enrolled in the study. Among them 138 were male and 99 were female. The youngest patient participated was 16 years old and the oldest was 86 years old (Table 2). The commonest age group was $40-49$ years, followed by $50-59$ and 30-39 years respectively. The average hemoglobin was $7.8 \mathrm{gm} \%$. The lowest hemoglobin in the series was $2.8 \mathrm{gm} \%$. It was less than 6 in 61 cases, more than 8 in 84 cases and between 6 and 8 in 92 cases. Peripheral blood smear showed hypochromic picture in 140 cases, macrocytic picture in 26 cases and the morphology was normocytic normochromic in 71 cases. Blood loss and iron deficiency was the main culprit for hypochromic morphology. Among which, variceal bleeding leading to anemia was seen in 52 cases, NSAID induced GI bleeding in 22 cases, peptic ulcer in 18 cases, hookworm infestation in 6 cases, nutritional iron deficiency and anemia of chronic diseases in remaining cases. 
Table 2: Age distribution of patients with anemia in medical wards of TUTH

$\begin{array}{lll}\text { S. No. } & \text { Age group (yrs) } & \text { No. of cases } \\ 1 . & <20 & 22 \\ 2 . & 20-29 & 36 \\ 3 . & 30-39 & 41 \\ 4 . & 40-49 & 46 \\ 5 . & 50-59 & 43 \\ 6 . & 60-69 & 27 \\ 7 . & >70 & 22 \\ \text { Total } & & \mathbf{2 3 7}\end{array}$

Among the 26 cases having macrocytic picture in peripheral blood smear, 11 had megaloblastic changes in bone marrow examination. Out of them, 6 had vitamin $B_{12}$ and 5 had folate deficiency. Remaining 15 patients having macrocytic picture were having associated chronic liver disease and hypothyroidism. Among the 71 patients having normocytic normochromic blood picture, 8 had hemolytic anemia, 11 had aplastic anemia and remaining were having anemia of chronic disease mainly chronic kidney disease.

Regarding treatment, 84 patients were transfused blood. These group included cases of acute anemia mainly due to GI bleeding and other cases of severe anemia. Vitamin $\mathrm{B}_{12}$ and folate was given to confirmed cases of megaloblastic anemias. Most of the patients received iron therapy as well. Out of total 237 patients included in the study, in-hospital mortality was 28 . The expired patients were mainly cases of variceal bleeding and chronic kidney disease.

\section{Discussion}

Anemia is a common clinical condition in patients admitted in medical wards. ${ }^{1}$ Most of the patients were having some other medical problems and were having associated anemia. As nutritional iron deficiency is very common and people having hemoglobin more than 10 without other comorbidities rarely seek medical suggestions in our set-up, patients having hemoglobin less than 10 were included in the study. Males are affected more than females, more likely due to higher occurrence of alcohol consumption and its complications as well as better access of males to hospital. The commonest age group was $40-49$ years because this age group was most affected by alcoholic liver disease and cirrhosis; the cases which are commonly referred to a tertiary care center like TUTH. The patient having lowest hemoglobin i.e., $2.8 \mathrm{gm} \%$ was a referred case from remote district and was found to be having hookworm infestation.
This reflects that chronic anemia is well compensated. ${ }^{2,4}$

\section{Conclusions}

As chronic blood loss and iron deficiency are among the leading causes of anemia, hypochromic and microcytic picture was the predominant picture in peripheral blood smear. On the other hand, megaloblastic anemia and aplastic anemia both are less common than iron deficiency anemia, both being present in only 11 patients. Among the 71 patients having normocytic normochromic blood picture, majority were having chronic kidney disease because TUTH is a tertiary referral centre for chronic renal failure. In-hospital mortality due to anemia alone is lower in tertiary care centers, but the mortality in our study is due to associated comorbid conditions like chronic renal failure and variceal upper GI bleeding. ${ }^{4}$

\section{References}

1. Lee GR, Foerster J, Lukens J. Wintrobe's clinical hematology. 10th ed. Baltimore, Md: Lippincott, Williams \& Wilkins; 1999.

2. Beutler E, Lichtman MA, Coller BS. Williams hematology. 6th ed. New York: McGraw-Hill; 2000.

3. Recommendations to prevent and control iron deficiency in the United States. Centers for Disease Control and Prevention. MMWR Recomm Rep. 1998 Apr 3;47(RR-3):1-29.

4. Hoffman R, Benz EJ Jr, Shattil SJ. Hematology: basic principles and practice. New York: Churchill Livingstone; 1998.

5. Oliveira MA, Osório MM, Raposo MC. Socioeconomic and dietary risk factors for anemia in children aged 6 to 59 months. J Pediatr (Rio J). 2007;83(1):39-46.

6. Hébert PC, Wells G, Blajchman MA, Marshall J, Martin C, Pagliarello G, et al. A multicenter, randomized, controlled clinical trial of transfusion requirements in critical care. Transfusion Requirements in Critical Care Investigators, Canadian Critical Care Trials Group. $\mathrm{N}$ Engl J Med. 1999 Feb 11;340(6):409-17.

7. Bush RL, Pevec WC, Holcroft JW. A prospective, randomized trial limiting perioperative red blood cell transfusions in vascular patients. Am J Surg. 1997 Aug;174(2):143-8.

8. Bracey AW, Radovancevic R, Riggs SA, Houston S, Cozart H, Vaughn WK, et al. Lowering the hemoglobin threshold for transfusion in coronary artery bypass 
Anemia

procedures: effect on patient outcome. Transfusion. 1999 Oct;39(10):1070-7.

9. McIntyre LA, Fergusson DA, Hutchison JS, Pagliarello G, Marshall JC, Yetisir E, et al. Effect of a liberal versus restrictive transfusion strategy on mortality in patients with moderate to severe head injury. Neurocrit Care. 2006;5(1):4-9.

10. Corwin HL, Gettinger A, Pearl RG, Fink MP, Levy MM, Abraham E, et al. The CRIT Study: Anemia and blood transfusion in the critically ill-current clinical practice in the United States. Crit Care Med. 2004 Jan;32(1):3952 .

11. Vincent JL, Baron JF, Reinhart K, Gattinoni L, Thijs L, Webb A, et al. Anemia and blood transfusion in critically ill patients. JAMA. 2002 Sep 25;288(12):1499-507.

12. Van Meter KW. A systematic review of the application of hyperbaric oxygen in the treatment of severe anemia: an evidence-based approach. Undersea Hyperb Med. 2005 Jan-Feb;32(1):61-83. 